\title{
Towards 3D self-assembled rolled multiwall carbon nanotube structures by spontaneous peel off
}

Jonathan Quinson ${ }^{1,2}$

\author{
Full Research Paper \\ Address: \\ ${ }^{1}$ Department of Chemistry, University of Copenhagen, \\ Universitetsparken 5, 2100 Copenhagen $\varnothing$, Denmark and ${ }^{2}$ Work \\ carried out at: Department of Materials, University of Oxford, Parks \\ Road, Oxford OX1 3PH, United Kingdom \\ Email: \\ Jonathan Quinson - jonathan.quinson@chem.ku.dk \\ Keywords: \\ chemical vapor deposition; multiwall carbon nanotubes; nitrogen \\ doping; peel off; rolled carbon nanotubes
}

Beilstein J. Nanotechnol. 2020, 11, 1865-1872. https://doi.org/10.3762/bjnano.11.168

Received: 10 October 2020

Accepted: 18 November 2020

Published: 18 December 2020

Associate Editor: S. R. Cohen

(C) 2020 Quinson; licensee Beilstein-Institut. License and terms: see end of document.

\begin{abstract}
Controlling the 3D assembly of individual nanomaterials can be a challenging task. However, it opens up opportunities for the production of increasingly complex nanostructures. Unusual rolled multiwall carbon nanotube structures are synthesized here by simply inducing a change of precursor composition during the growth of multiwall carbon nanotube forests. The multiwall carbon nanotube structures are comprised of nitrogen-doped and undoped sections, and are obtained via a detailed peel off and roll mechanism. These results open new doors for the development of increasingly complex nanostructures.
\end{abstract}

\section{Introduction}

Carbon nanotubes (CNTs) are popular materials used in various applications [1]. These tubular hollow carbon nanomaterials have proven to be useful in multiple scientific fields [2-6] Complex structures with increasingly controlled properties are obtained having CNTs as building blocks. For instance, 3D structures made of CNTs can be synthesized on supports as selfassembled "forests" [7]. These structures have been employed in biomedical applications [7], chromatography [8], or filtration [9]. However, support-free 3D structures typically require extra synthesis steps. "Sponges" or "cages" can be produced by freeze-drying preformed CNTs [10] or by etching template materials [11].
A way to tune CNT properties further is to introduce other elements in the carbon network (e.g., nitrogen [12-14]). This so-called doping tunes CNT properties for specific applications. A step further to design more complex CNTs is to develop materials with a composition change (e.g., CNT structures displaying both properties of nitrogen-doped and undoped carbon along the same CNT [15]). A structural change in CNTs is achieved by tuning experimental parameters during CNT synthesis [16].

To date, CNTs with so-called intratubular junctions have been used exclusively for electronic applications due to their $\mathrm{p}-\mathrm{n}$ 
junction behavior [17-19]. The potential of CNTs with junctions to serve as building blocks for other more complex nanomaterials remains underexploited. We recently proposed new approaches to prepare such complex materials [16]. In this work it is explored how template-free 3D nanostructures can be obtained by using CNTs with junctions.

\section{Results}

To develop new ways to induce a compositional change within CNTs and to optimize the formation of complex CNT structures, the possibility to couple aerosol-assisted chemical vapor deposition (AACVD) [20] and chemical vapor deposition (CVD) was explored [16]. For detailed synthesis and characterization protocols, including control experiments, please see Experimental section. Undoped sections of multiwall CNTs (MWCNTs) grown from toluene or acetylene, are referred as "C" whereas nitrogen-doped sections, grown under ammoniacontaining atmosphere or using benzylamine, are referred as "N" [21]. The chronological order of the grown sections is shown by the index with an ascending numerical order. Therefore, the two synthesis sequences described here lead to $\mathrm{C}_{1} / \mathrm{N}_{2} / \mathrm{C}_{3}$ and $\mathrm{C}_{1} / \mathrm{N}_{2} / \mathrm{C}_{3} / \mathrm{N}_{4}$ structures.

The coupling of AACVD and CVD leads to MWCNTs with a compositional change [16]. In addition to obtaining the expected vertically aligned MWCNT forests or carpets [22], less conventional and complex structures were also developed and their formation mechanism is proposed in this study. In a typical AACVD synthesis, MWCNTs grow perpendicular to the substrates (i.e., quartz reactor walls or silicon wafers [23]). Under the conditions of the present study, it is observed, by the naked eye, that layers peel off from the MWCNT forests after synthesis. This is observed without the need to apply any mechanical stress. However, when this phenomenon occurs, it is not possible to identify an area without MWCNTs. In other words, despite the peeling off the substrates remain dark, which indicates that MWCNTs are still present.

In order to characterize the nature of the peeled-off layer, scanning electron microscopy (SEM) characterization was performed. Figure 1 displays an SEM micrograph of a sample with a $\mathrm{C}_{1} / \mathrm{N}_{2} / \mathrm{C}_{3} / \mathrm{N}_{4}$ structure in which the peeling off was first observed by the naked eye. Based on a morphological characterization from a previous work [16], four distinct sections are identified along the MWCNT forest. From top to bottom (bottom is marked by the silicon substrate at the bottom of the image), one can see a "wavy", a "straight", another "wavy", and a final "straight" section. A wavy structure is the expected morphology for undoped MWCNTs, whereas a straight section is expected for N-doped MWCNTs [6,16,21]. Thus, the sequence observed is in agreement with the synthesis sequence per- formed and with a root-growth mechanism previously detailed $[16,24,25]$. It is also in agreement with the Raman characterization detailed below.

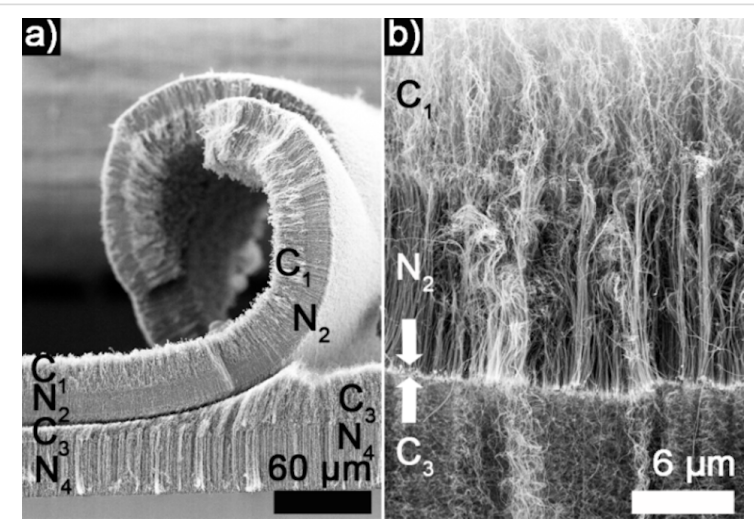

Figure 1: (a) SEM micrograph of a $\mathrm{C}_{1} / \mathrm{N}_{2} / \mathrm{C}_{3} / \mathrm{N}_{4}$ structure in which a break between the $\mathrm{N}_{2}$ and $\mathrm{C}_{3}$ part leads to MWCNTs layers to peel off. (b) SEM micrograph of $C_{1} / N_{2} / C_{3}$ structures in which the $N_{2} / C_{3}$ interface displays iron-based particles. The bright line between the two arrows in the image is associated with a strong morphological change from straight to wavy MWCNTs.

The SEM analysis reveals that the peeled-off layers are $\mathrm{C}_{1} / \mathrm{N}_{2}$ sections detached from another supporting $\mathrm{C}_{3} / \mathrm{N}_{4}$ MWCNT layer. This implies that only a few layers of MWCNTs are disconnected from the forest. Such peeling off is not observed when no compositional change is induced (i.e., if only undoped or nitrogen-doped MWCNTs are synthesized [21]). The peeling off seems to happen preferentially at a $\mathrm{N}_{x} / \mathrm{C}_{x+1}$ interface, which is weaker and less continuous than a $\mathrm{C}_{x} / \mathrm{N}_{x+1}$ interface, as we recently documented [16] and as further detailed in the Discussion section.

According to the hypothesis that the peeling off is promoted by a challenging formation of $\mathrm{N}_{x} / \mathrm{C}_{x+1}$ junctions, the $\mathrm{C}_{1} / \mathrm{N}_{2} / \mathrm{C}_{3}$ structure was studied further. The SEM micrograph of a $\mathrm{C}_{1} / \mathrm{N}_{2} / \mathrm{C}_{3}$ structure (Figure $1 \mathrm{~b}$ ) shows three different sections: From top to bottom, there is a wavy, a straight, and another wavy section. This sequential changes in the morphology is in agreement with the synthesis sequence used. The interface between the expected $\mathrm{N}_{2}$ and $\mathrm{C}_{3}$ sections is marked by a brighter line.

Raman spectra of undoped MWCNTs and nitrogen-doped MWCNTs are significantly different $[6,16,21]$. Undoped MWCNTs are characterized by an intensity ratio between D and $G$ peaks smaller than 1 and by a strong $2 \mathrm{D}$ peak, whereas nitrogen-doped MWCNTs show an intensity ratio between D and $\mathrm{G}$ peaks of approx. 1 and a less pronounced 2D peak [12,21]. The $D, G$ and $2 D$ peaks of a $C_{1} / N_{2} / C_{3}$ structure is shown in Figure 2. The $\mathrm{D}$ peak refers to a defect in the 
MWCNT structure. An intense D peak (relative to the G peak intensity) correlates to higher defects, for instance, induced by nitrogen doping. The $\mathrm{G}$ and $2 \mathrm{D}$ peaks are related to the graphitization of MWCNTs. An intense G peak (relative to the D peak intensity) and the presence of a 2D peak indicate a more graphitized MWCNT.

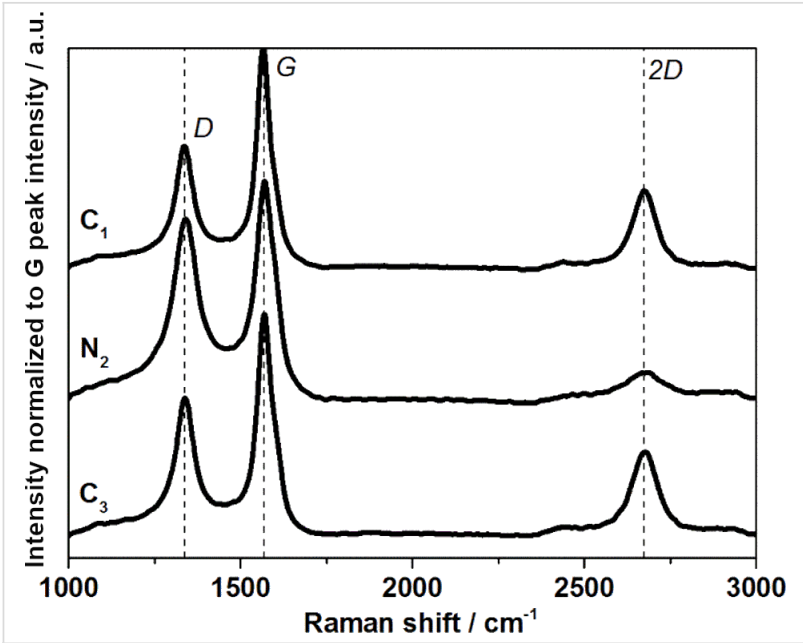

Figure 2: Raman spectra of each section of a $\mathrm{C}_{1} / \mathrm{N}_{2} / \mathrm{C}_{3}$ structure.

Conveniently, the structures obtained here have sections that are long enough $(>10 \mu \mathrm{m})$ to be unambiguously focused by a Raman laser, using the optical lens of a Raman microscope [16]. Typical Raman spectra features obtained along $\mathrm{C}_{1} / \mathrm{N}_{2} / \mathrm{C}_{3}$ structures are shown in Figure 2. In good agreement with the synthesis sequence performed, the Raman spectra show typical features of undoped MWCNTs for the expected C sections, and typical features of nitrogen-doped MWCNTs for the expected N sections. These characteristic features in the Raman spectra were observed in all MWCNT structures with different sections investigated in this study.

Under the experimental conditions leading to the $\mathrm{C}_{1} / \mathrm{N}_{2} / \mathrm{C}_{3}$ structure, more peeling off is observed. After synthesis, a simple bending of the quartz tube, which is used as a reactor, enables the collection of several milligrams of a black powder. SEM micrographs of the collected powder are shown in Figure 3 . The powder observed is not mechanically detached from any substrate where the MWCNT growth is expected to occur. Conversely, this material is likely to be MWCNTs that peeled off from the carpet and detached from MWCNT underlayers, with the latest layer still connected to the substrate (Figure 1a).

\section{Discussion}

To clarify the formation mechanism of the unusual structures shown in Figure 3, control experiments were conducted in

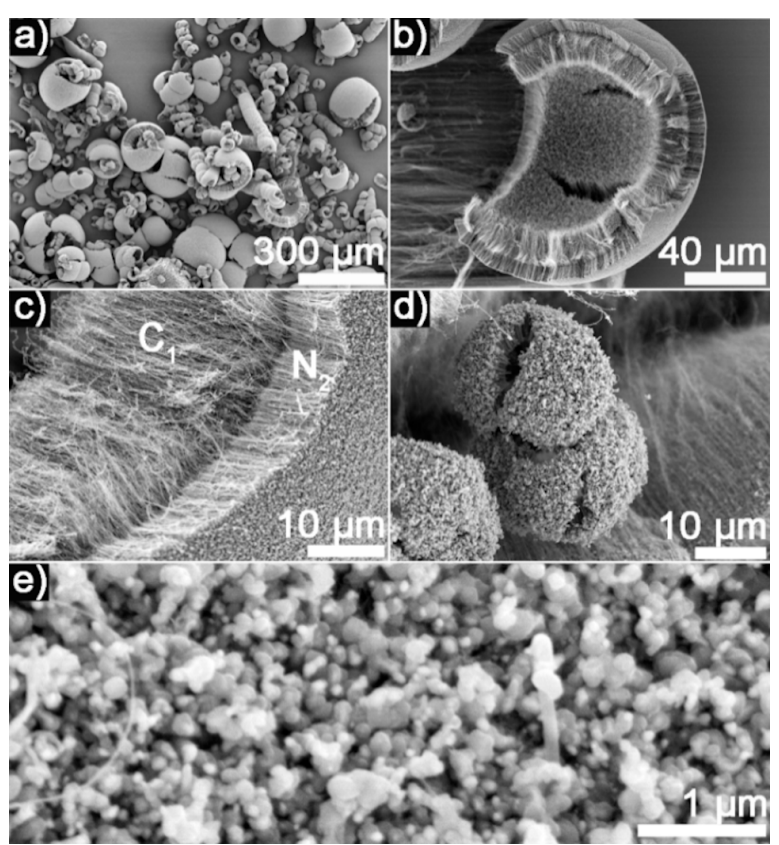

Figure 3: (a-e) SEM micrographs of the powder collected after the synthesis of $C_{1} / N_{2} / C_{3}$ structures. (e) The outer surface of the rolled structure, brighter in the SEM micrograph, is made of iron catalyst particles.

which only $\mathrm{C}_{1} / \mathrm{N}_{2}$ or $\mathrm{C}_{2} / \mathrm{N}_{1}$ structures were formed. SEM characterization of the related materials is reported in Supporting Information File 1, Figure S1 and Figure S2. In these control experiments, no rolled structures similar to those reported in Figure 3 were observed. The $\mathrm{C}_{1} / \mathrm{N}_{2}$ structures are more continuous than the $\mathrm{C}_{2} / \mathrm{N}_{1}$ structures. At the root of the $\mathrm{C}_{1} / \mathrm{N}_{2}$ forest, structures compatible with relatively large nanoparticles (approx. $100 \mathrm{~nm}$ ) are identified. These are attributed to Fe metal catalysts formed during the synthesis and from which MWCNTs grow, assuming a root-growth mechanism [16,26]. For $\mathrm{N}_{1} / \mathrm{C}_{2}$ structures, it is not straightforward to observe the same structures at the bottom of the CNT forest, although clear structures related to Fe nanoparticles are observed at the $\mathrm{N}_{1} / \mathrm{C}_{2}$ interface (see discussion below Figure 4). This confirms that creating a $\mathrm{N}_{1} / \mathrm{C}_{2}$ interface is challenging.

It is established that the inner diameter of MWCNTs increases with the diameter of the nanoparticle from which they grow [26]. It is established that N-MWCNTs have a larger inner diameter than MWCNTs without an intended doping [6,12,21]. This is also observed in $\mathrm{N}_{1} / \mathrm{C}_{2}$ structures (Figure 4) in which the $\mathrm{N}$ section has a larger inner diameter and the $\mathrm{C}$ section has a smaller inner diameter [16]. Thus, the size of a catalyst to grow a N-MWCNT is larger than that to grow an undoped C-MWCNT. This size is determined by the experimental conditions, such as the presence or absence of $\mathrm{N}$ atoms. This is related to the fact that smaller nanoparticles are more difficult to 


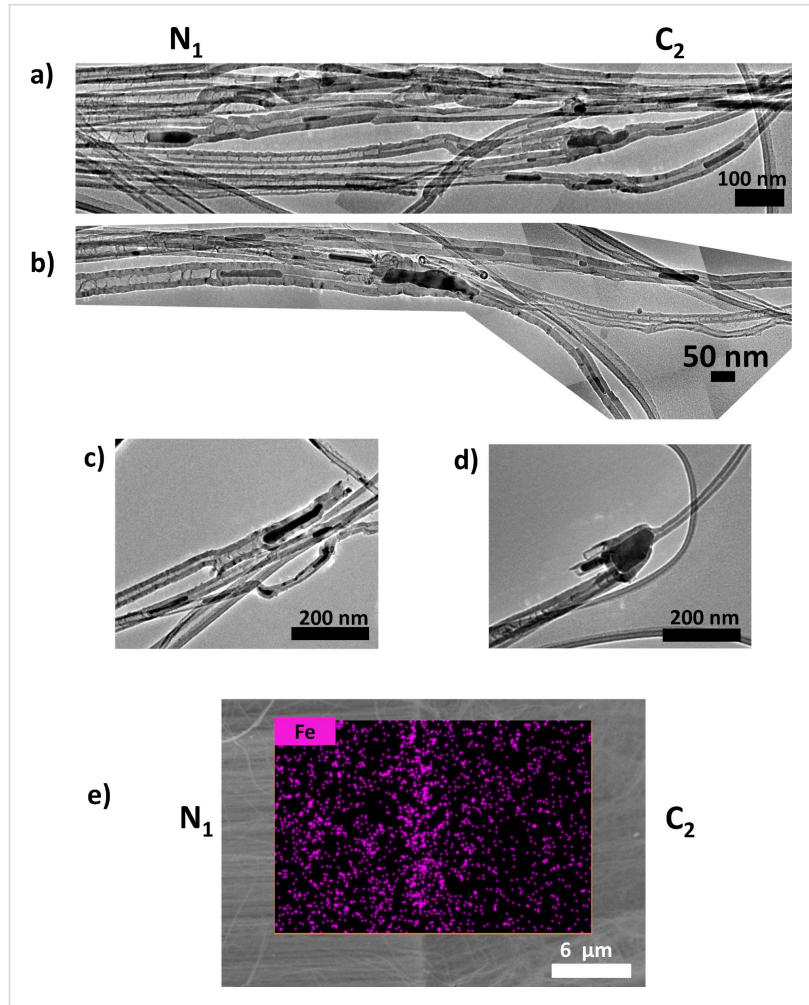

Figure 4: (a-d) TEM characterization of a $\mathrm{N}_{1} / \mathrm{C}_{2}$ interface marked by the presence of metal (iron) nanoparticles before and after a clear change in the typical structure of $\mathrm{N}$ (larger inner diameter and corrugated structure) and $\mathrm{C}$ (smaller inner diameter) sections. Panels $(\mathrm{a}, \mathrm{d})$ were obtained by superimposing several TEM micrographs, all taken at the same magnification along the $N_{1} / C_{2}$ interface. (c,d) Examples of individual MWCNTs with a clear change of structure before and after the interface, which is marked by a nanoparticle (dark structure in the TEM images). (c) Broken MWCNT structure after the interface, whereas in (d) the structure remains intact. (e) SEM backscattered images and the related Fe EDS mapping at a $\mathrm{N}_{1} / \mathrm{C}_{2}$ interface.

be identified at the root of MWCNTs in $\mathrm{N}_{1} / \mathrm{C}_{2}$ junctions than larger nanoparticles at the root of MWCNT in $\mathrm{C}_{1} / \mathrm{N}_{2}$ junctions (Supporting Information File 1, Figure S1).

A $C_{1} / N_{2}$ junction, therefore, requires a size increase of the nanocatalyst whereas an $\mathrm{N}_{1} / \mathrm{C}_{2}$ junction requires a size decrease of the nanocatalyst. For the synthesis performed, a size increase is relatively easy to be achieved since ferrocene, source of the iron atoms, is constantly provided (see Experimental section). However, a size decrease is possible mainly by a size change of the catalyst nanoparticle and by some "loss" of the catalyst (e.g., within the MWCNT). This scenario is supported by EDS and TEM data (Figure 4). Nanoparticles with higher atomic weight ratio appear as white features in SEM micrographs and as dark features in TEM micrographs. SEM characterization of vertically aligned MWCNTs, together with Raman spectra acquired on the same cross section, unambiguously assign a given morphology to a given structure in a confirmed root-growth mechanism, since the sample can be kept on a sub- strate [16]. TEM characterization is more challenging since the information regarding the relative position of the different sections is lost during sample preparation. Nevertheless, on MWCNT structures with only one junction a change in structure can still be related to the precursor used. In the case of $\mathrm{N}_{1} / \mathrm{C}_{2}$ junctions (Figure $4 \mathrm{a}$ and Figure $4 \mathrm{~b}$ ) the interface between the two expected sections is conveniently marked by darker features, which correspond well to the lighter features observed in SEM micrographs (Supporting Information File 1, Figure S1 and Figure S2). These features are related to ironbased nanoparticles, as confirmed by EDS. An area with higher intensity of $\mathrm{Fe}$ is observed at the interface of a $\mathrm{N}_{1} / \mathrm{C}_{2}$ structure (Figure 5e) as reported in our previous work [16].

On each side of the nanoparticle marking the $\mathrm{N}_{1} / \mathrm{C}_{2}$ interface, the inner diameter of the tube is drastically changed. One side shows a relatively large inner diameter (in agreement with the N-MWCNT structure) whereas the other side shows a relatively small inner diameter (in agreement with undoped MWCNT). It is also noted that on the side of the smaller inner diameter, the MWCNT structure is often broken. Figure $4 \mathrm{c}$ highlights the weaker nature of the $\mathrm{N}_{1} / \mathrm{C}_{2}$ interface.

Taking all this information into account, a mechanism for the formation of $\mathrm{C}_{1} / \mathrm{N}_{2}$ and $\mathrm{N}_{1} / \mathrm{C}_{2}$ structures is suggested (Figure 5). This schematic representation is based on the experimental results of a confirmed root-growth mechanism, on the relationship between the size of the catalyst particle, and on the diameter of MWCNTs and N-MWCNTs. In addition, it is in agreement with $[6,12,16,20,21,24,26-30]$ and it builds up upon the formation of $\mathrm{C}_{1} / \mathrm{N}_{2}$ and $\mathrm{N}_{1} / \mathrm{C}_{2}$ structures, as proposed in [16]. The need for a size decrease to form a $\mathrm{N}_{1} / \mathrm{C}_{2}$ junction acts as a constraint on the MWCNT structure, leading to a weaker junction that often breaks (which is not easily observed in a $\mathrm{C}_{1} / \mathrm{N}_{2}$ junction).

In the case of only one junction, no peeling off is observed (Supporting Information File 1, Figure S1 and Figure S2, and [16]). Considering that MWCNT forests of vertically aligned N-MWCNTs or C-MWCNTs are easily obtained [12,21], it is expected that, even in the case of a weak junction that ultimately breaks, the two sections will simply stay on top of each other. In order to promote the roll-up, the section to be developed cannot be uniform and the layer that is peeled off needs to show a more complex structure. In this work, $\mathrm{C}_{1} / \mathrm{N}_{2}$ junctions with different lengths are examples of suitable complex structures. It is clear from the SEM characterization that the structure of N-MWCNTs is different from the structure of C-MWCNTs: It is curly for C sections and straight for $\mathrm{N}$ sections (Figure 1, Supporting Information File 1, Figure S1 and Figure S2, and [16]). This is likely related to different inter- 


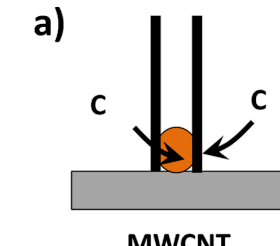

Small inner diameter Small nanoparticle catalyst

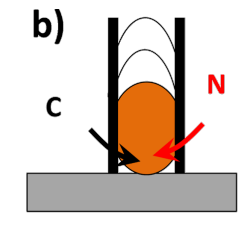

N-MWCNT

Larger inner diameter

Larger nanoparticle catalyst

c) $\mathrm{C}_{1} / \mathrm{N}_{2}$

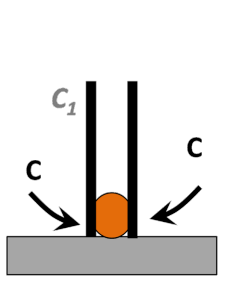

Catalyst particle size increase
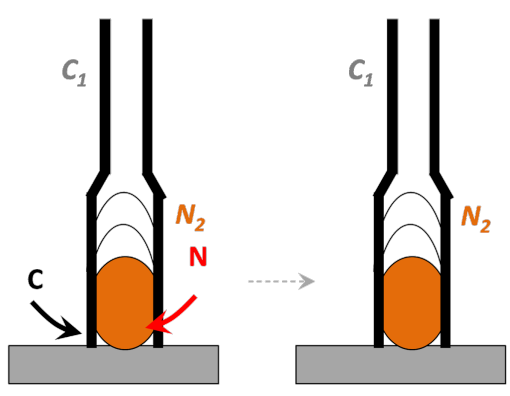

d) $\mathrm{N}_{1} / \mathrm{C}_{2}$
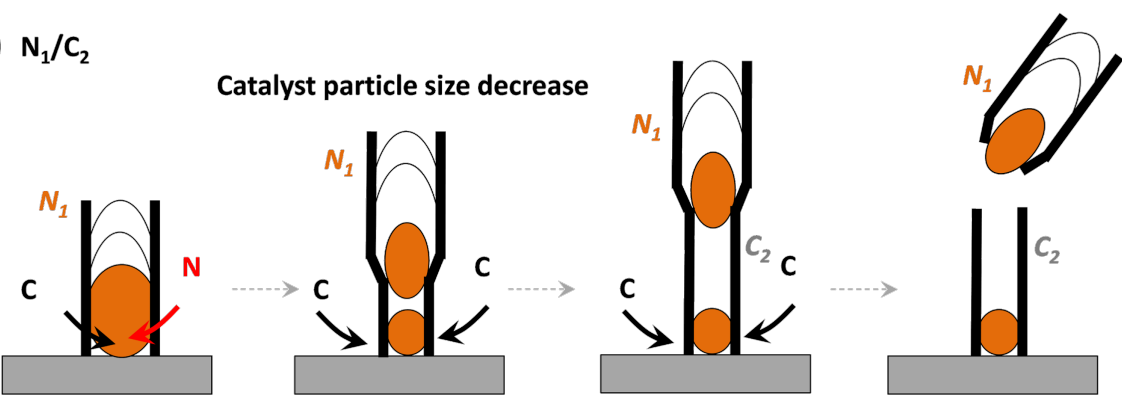

Figure 5: Schematic representing the growth mechanism and the relation between inner diameter and catalyst nanoparticle size and position for (a) MWCNT, (b) N-MWCNT, (c) $\mathrm{C}_{1} / \mathrm{N}_{2}$, and (d) $\mathrm{N}_{1} / \mathrm{C}_{2}$ MWCNT structures.

actions between different sections. When a composition change is performed and a $\mathrm{N}_{x} / \mathrm{C}_{x+1}$ is added to a $\mathrm{C}_{x-1} / \mathrm{N}_{x}$ structure, the detachment of the $\mathrm{N}_{x}$ section from the $\mathrm{C}_{x+1}$ section is favored (Figure 1 and Figure 5). Since $\mathrm{C}_{x-1} / \mathrm{N}_{x}$ is stronger and more continuous, its entire structure peels off and, thus, becomes free-standing. Different interactions between $\mathrm{C}_{x-1}$ and $\mathrm{N}_{x}$ sections [31] lead to the rolling of the free-standing structure, which eventually leads to the MWCNT rolled forest configuration.

Another observation that strongly supports the proposed formation mechanism is the curved and rolled aspect of the structures (Figure 3a-d) and the fact that the outer part of the rolled MWCNTs is made of particle-like structures (Figure 3e). These iron nanoparticles formed as catalyst from ferrocene, under certain reaction conditions [21], appear in the SEM micrographs as brighter features and are typically found at the $\mathrm{N}_{x} / \mathrm{C}_{x+1}$ interface (Figure 1b, Figure 4, Figure 5, Supporting Information File 1, Figure S1 and Figure S2, and [16]). In
Figure $1 b$, these features can be observed at the $\mathrm{N}_{2} / \mathrm{C}_{3}$ interface. After peeling off and rolling (Figure 1a), the $\mathrm{N}$ section of the broken $\mathrm{N}_{x} / \mathrm{C}_{x+1}$ interfaces becomes the outer surface of the observed rolls. Therefore, it is not surprising that the presence of iron particles at the $\mathrm{N}_{x} / \mathrm{C}_{x+1}$ interface leads to the presence of iron particles on the outer surface of the obtained rolled $\mathrm{C}_{x-1} / \mathrm{N}_{x}$ structures.

In summary, the rolled structures reported here display a curvature that is not usually reported for MWCNT forests or MWCNTs grown under a hydrocarbon flow [21,23]. Control experiments show that creating $\mathrm{C}_{1} / \mathrm{N}_{2}$ or $\mathrm{N}_{1} / \mathrm{C}_{2}$ interfaces does not lead to rolled structures (Supporting Information File 1, Figure S1 and Figure S2). Thus, two junctions are necessary to develop complex structures. The formation of MWCNT structures with a spherical shape is likely derived from a combination of peeling off and rolling phenomena. The peeling off is achieved by developing weak interfaces between different sections of a MWCNT forest. Developing a $\mathrm{N}_{x} / \mathrm{C}_{x+1}$ is an ex- 
ample of how to develop such a weak interface. The driving force behind the rolling phenomena is not yet fully established. However, it is strongly related to the formation of a $\mathrm{C}_{x-1} / \mathrm{N}_{x}$ interface in which the length of the $\mathrm{C}$ and $\mathrm{N}$ sections may play a role. More importantly, different interactions are likely to be developed between MWCNTs within the same section, as indicated by the different morphologies, different diameters, and the apparent packing of MWCNTs. This eventually promotes the resulting spherical geometry by inducing different mechanical forces between the MWCNTs as they become free-standing after the peel off.

\section{Conclusion}

In this study, the controlled synthesis and characterization of rolled self-assembled structures made of MWCNTs is presented. The formation of these structures relies on the formation of MWCNT forests with different sections showing different compositions along the forest, and on the development of a weaker interface between some sections, such as a change in composition from nitrogen-doped to undoped MWCNTs. A suggested peel off and roll formation mechanism is detailed. The results presented here open routes for the production of complex support-free and template-free 3D structures made of MWCNTs with intratubular junctions between sections of different compositions. The approach introduced paves the way for a simple design of new complex 3D sphere-like MWCNT nanostructures whose properties are yet to be fully explored.

\section{Experimental Synthesis}

MWCNTs with junctions were prepared by following a general approach detailed recently [16]. MWCNTs were synthesized at $800{ }^{\circ} \mathrm{C}$ with argon (Ar, 99.999\%, BOC) as the carrier flow using an AACVD setup [12,23]. Briefly, MWCNTs were grown on silicon wafer substrates $\left(10 \times 20 \mathrm{~mm}^{2}\right.$, Sibert, UK) by using an aerosol CVD setup consisting of a piezoelectric generator, a quartz tube $(2.2 \mathrm{~cm}$ inner diameter), a $50 \mathrm{~cm}$ long horizontal tube furnace, a gas flow controller, and an acetone gas trap. The total gas flow was $2500 \mathrm{sccm}$ for all experiments. In order to obtain different compositions within the MWCNTs, different sequences of different precursors were used during the same synthesis protocol. The length of the different sections was controlled by changing the time of injection of the relevant precursors (the longer the time of injection, the longer the section).

In a first approach, the synthesis of $\mathrm{C}_{1} / \mathrm{N}_{2} / \mathrm{C}_{3}$ structures was performed as follows. First, a liquid precursor consisting of toluene $(99.9 \%$, Sigma-Aldrich) and 5 wt $\%$ of ferrocene $(98 \%$, Aldrich, purified via sublimation at $90{ }^{\circ} \mathrm{C}$ prior to use) was injected into the furnace with Ar gas flow at $2000 \mathrm{sccm}$ in a first precursor line (Supporting Information File 1, Figure S3) for $3 \mathrm{~min}$. In a second precursor line, $500 \mathrm{sccm}$ of Ar were used. Next, while the same ferrocene and toluene mixture was injected into the furnace, ammonia ( $\geq 99.98 \%$, BOC) was added to the carrier gas at $30 \mathrm{sccm}$ for $15 \mathrm{~min}$. Finally, acetylene (industrial grade, BOC) was used as a gas precursor at $100 \mathrm{sccm}$ with hydrogen ( $\geq 99.995 \%$, BOC) at $30 \mathrm{sccm}$ in an argon flow for $20 \mathrm{~min}$. For this last step, the injection of toluene and ferrocene mixture was stopped. The catalyst for the formation of MWCNTs was formed from the initially introduced ferrocene precursor [21].

In a second approach, the synthesis to obtain $\mathrm{C}_{1} / \mathrm{N}_{2} / \mathrm{C}_{3} / \mathrm{N}_{4}$ structures was as follows (Supporting Information File 1, Figure S4). First, a liquid precursor consisting of toluene and $5 \mathrm{wt} \%$ of ferrocene was injected into the furnace for $5 \mathrm{~min}$. Next, a solution of benzyalmine ( $\geq 99 \%$, Fluka) without ferrocene was injected for $15 \mathrm{~min}$. Then, the same solution of toluene and $5 \mathrm{wt} \%$ of ferrocene was used as a precursor and injected for $10 \mathrm{~min}$. Finally, a solution of benzyalmine without ferrocene was injected for $20 \mathrm{~min}$.

In control experiments only two steps were used. As a first step of one type of control experiment, $5 \mathrm{wt} \%$ of ferrocene in toluene was continuously injected, for $7 \mathrm{~min}$, in the hot part of the furnace using an Ar flow of $2000 \mathrm{sscm}$ in the first precursor line, while $500 \mathrm{sccm}$ of Ar was mixed with this flow at the furnace entrance of the second precursor line (Supporting Information File 1, Figure S3, step 1). In the second step the conditions in the first line were unchanged whereas the second line allowed a flow of $\mathrm{NH}_{3}$ at $30 \mathrm{sccm}$ with $470 \mathrm{sccm}$ of Ar for 30 min (Supporting Information File 1, Figure S3, step 2). In another type of control experiment, the two previous steps were performed in the opposite order. In the first step, $5 \mathrm{wt} \%$ of ferrocene in toluene was injected with $2000 \mathrm{sccm}$ Ar in the first line while $470 \mathrm{sccm} \mathrm{Ar}$ and $30 \mathrm{sccm} \mathrm{NH}_{3}$ were flown in the second line for $15 \mathrm{~min}$. In the second step, $5 \mathrm{wt} \%$ of ferrocene in toluene was injected with $2000 \mathrm{sccm}$ Ar in the first line while $500 \mathrm{sccm}$ Ar was flown in the second line for $4 \mathrm{~min}$.

\section{Characterization}

MWCNT structures were characterized by SEM (Jeol 840F operated at $5 \mathrm{kV}$ and a Zeiss NVision FIB microscope equipped with an in-lens and a backscattered-electron detector, also operated at $5 \mathrm{kV}$ ) and by Raman spectroscopy (JY Horiba Labram Aramis imaging confocal Raman microscope equipped with a $532 \mathrm{~nm}$ green laser). The Raman spectra recorded were consistent within each section with the characteristic spectra of undoped or N-doped MWCNTs. The materials were collected from the furnace after synthesis and deposited onto suitable holders in powder or in as-prepared form on the silicon wafers. For clarity, cross section images of MWCNT forests were ob- 
tained by simply cleaving the silicon wafer after MWCNT growth, in order to expose the inside of the MWCNT forests for both Raman and SEM. This was simply achieved by applying mechanical pressure on the edge of the silicon wafer. EDS mapping and associated SEM backscattered images were recorded with a Hitachi TM3000 table top SEM operated at $15 \mathrm{kV}$. For Fe mapping, a $6.399 \mathrm{keV}$ peak intensity was used. Further characterization details can be found in [16]. Nitrogen doping is expected to be in the range of $0.5-2$ atom \%, according to previous reports $[12,21,32]$.

\section{Supporting Information}

\section{Supporting Information File 1}

Experimental section.

Schemes of the synthesis approaches and further SEM

characterization.

[https://www.beilstein-journals.org/bjnano/content/

supplementary/2190-4286-11-168-S1.pdf]

\section{Acknowledgements}

Prof Nicole Grobert and the Nanomaterials by Design research group at the Department of Materials at the University of Oxford are thanked for fruitful discussions and for providing consumables and access to equipment.

\section{Funding}

The Engineering and Physical Sciences Research Council (EPSRC), UK, is thanked for supporting this work via an EPSRC-DTA award (EP/J500495/1).

\section{ORCID ${ }^{\circledR}$ iDs}

Jonathan Quinson - https://orcid.org/0000-0002-9374-9330

\section{References}

1. Schnorr, J. M.; Swager, T. M. Chem. Mater. 2011, 23, 646-657. doi:10.1021/cm102406h

2. Saifuddin, N.; Raziah, A. Z.; Junizah, A. R. J. Chem. 2013, No. 676815. doi:10.1155/2013/676815

3. Liu, J.; Liu, C.-T.; Zhao, L.; Zhang, J.-J.; Zhang, L.-M.; Wang, Z.-B. Int. J. Hydrogen Energy 2016, 41, 1859-1870. doi:10.1016/j.ijhydene.2015.11.103

4. Yang, H.; Zhang, X.; Zou, H.; Yu, Z.; Li, S.; Sun, J.; Chen, S.; Jin, J.; Ma, J. ACS Sustainable Chem. Eng. 2018, 6, 7918-7923. doi:10.1021/acssuschemeng.8b01157

5. Das, R.; Leo, B. F.; Murphy, F. Nanoscale Res. Lett. 2018, 13, 183. doi:10.1186/s11671-018-2589-z

6. Quinson, J.; Hidalgo, R.; Ash, P. A.; Dillon, F.; Grobert, N.; Vincent, K. A. Faraday Discuss. 2014, 172, 473-496. doi:10.1039/c4fd00058g
7. Wang, S. G.; Wang, R.; Sellin, P. J.; Zhang, Q. Biochem. Biophys. Res. Commun. 2004, 325, 1433-1437. doi:10.1016/j.bbrc.2004.10.188

8. Saridara, C.; Mitra, S. Anal. Chem. (Washington, DC, U. S.) 2005, 77, 7094-7097. doi:10.1021/ac050812j

9. Ihsanullah. Sep. Purif. Technol. 2019, 209, 307-337. doi:10.1016/j.seppur.2018.07.043

10. Luo, S.; Luo, Y.; Wu, H.; Li, M.; Yan, L.; Jiang, K.; Liu, L.; Li, Q.; Fan, S.; Wang, J. Adv. Mater. (Weinheim, Ger.) 2017, 29, 1603549. doi:10.1002/adma.201603549

11. Sano, M.; Kamino, A.; Okamura, J.; Shinkai, S. Nano Lett. 2002, 2, 531-533. doi:10.1021/nl025525z

12. Koós, A. A.; Dowling, M.; Jurkschat, K.; Crossley, A.; Grobert, N. Carbon 2009, 47, 30-37. doi:10.1016/j.carbon.2008.08.014

13. Ning, X.; Li, Y.; Dong, B.; Wang, H.; Yu, H.; Peng, F.; Yang, Y. J. Catal. 2017, 348, 100-109. doi:10.1016/j.jcat.2017.02.011

14. Sumpter, B. G.; Meunier, V.; Romo-Herrera, J. M.; Cruz-Silva, E.; Cullen, D. A.; Terrones, H.; Smith, D. J.; Terrones, M. ACS Nano 2007, 1, 369-375. doi:10.1021/nn700143q

15. Wei, D.; Liu, Y.; Cao, L.; Fu, L.; Li, X.; Wang, Y.; Yu, G.; Zhu, D. Nano Lett. 2006, 6, 186-192. doi:10.1021/nl051955o

16. Quinson, J.; Dillon, F.; Nicholls, R.; Koos, A.; Vincent, K.; Grobert, N. ACS Appl. Nano Mater. 2020, 3, 7554-7562. doi:10.1021/acsanm.0c01199

17. Chai, Y.; Zhou, X. L.; Li, P. J.; Zhang, W. J.; Zhang, Q. F.; Wu, J. L. Nanotechnology 2005, 16, 2134-2137. doi:10.1088/0957-4484/16/10/027

18. Xiao, K.; Fu, Y.; Liu, Y. Q.; Yu, G.; Zhai, J.; Jiang, L.; Hu, W. P.; Shuai, Z. G.; Luo, Y.; Zhu, D. B. Adv. Funct. Mater. 2007, 17, 2842-2846. doi:10.1002/adfm.200600830

19. Hu, P.; Xiao, K.; Liu, Y.; Yu, G.; Wang, X.; Fu, L.; Cui, G.; Zhu, D. Appl. Phys. Lett. 2004, 84, 4932-4934. doi:10.1063/1.1760212

20. Castro, C.; Pinault, M.; Coste-Leconte, S.; Porterat, D.; Bendiab, N.; Reynaud, C.; Mayne-L'Hermite, M. Carbon 2010, 48, 3807-3816. doi:10.1016/j.carbon.2010.06.045

21. Koós, A. A.; Dillon, F.; Obraztsova, E. A.; Crossley, A.; Grobert, N. Carbon 2010, 48, 3033-3041. doi:10.1016/j.carbon.2010.04.026

22. Chen, H.; Roy, A.; Baek, J.-B.; Zhu, L.; Qu, J.; Dai, L. Mater. Sci. Eng., R 2010, 70, 63-91. doi:10.1016/j.mser.2010.06.003

23. Meysami, S. S.; Dillon, F.; Koós, A. A.; Aslam, Z.; Grobert, N. Carbon 2013, 58, 151-158. doi:10.1016/j.carbon.2013.02.044

24. Khodja, H.; Pinault, M.; Mayne-L'Hermite, M.; Reynaud, C. Nucl. Instrum. Methods Phys. Res., Sect. B 2006, 249, 523-526. doi:10.1016/j.nimb.2006.03.044

25. Kunadian, I.; Andrews, R.; Qian, D.; Pinar Mengüç, M. Carbon 2009, 47, 384-395. doi:10.1016/j.carbon.2008.10.022

26. Kumar, M.; Ando, Y. J. Nanosci. Nanotechnol. 2010, 10, 3739-3758. doi:10.1166/jnn.2010.2939

27. Ago, H.; Ishigami, N.; Yoshihara, N.; Imamoto, K.; Akita, S.; Ikeda, K.-i.; Tsuji, M.; Ikuta, T.; Takahashi, K. J. Phys. Chem. C 2008, 112, 1735-1738. doi:10.1021/jp709737q

28. Pattinson, S. W.; Ranganathan, V.; Murakami, H. K.; Koziol, K. K. K.; Windle, A. H. ACS Nano 2012, 6, 7723-7730. doi:10.1021/nn301517g

29. Tessonnier, J.-P.; Su, D. S. ChemSusChem 2011, 4, 824-847. doi:10.1002/cssc.201100175

30. Pattinson, S. W.; Diaz, R. E.; Stelmashenko, N. A.; Windle, A. H.; Ducati, C.; Stach, E. A.; Koziol, K. K. K. Chem. Mater. 2013, 25 , 2921-2923. doi:10.1021/cm401216q

31. Goswami, G. K.; Nandan, R.; Nanda, K. K. Carbon 2013, 56, 97-102. doi:10.1016/j.carbon.2012.12.079 
32. Bulusheva, L. G.; Okotrub, A. V.; Fedoseeva, Y. V.; Kurenya, A. G.;

Asanov, I. P.; Vilkov, O. Y.; Koós, A. A.; Grobert, N.

Phys. Chem. Chem. Phys. 2015, 17, 23741-23747.

doi:10.1039/c5cp01981h

\section{License and Terms}

This is an Open Access article under the terms of the Creative Commons Attribution License

(https://creativecommons.org/licenses/by/4.0). Please note that the reuse, redistribution and reproduction in particular requires that the author(s) and source are credited and that individual graphics may be subject to special legal provisions.

The license is subject to the Beilstein Journal of

Nanotechnology terms and conditions:

(https://www.beilstein-journals.org/bjnano/terms)

The definitive version of this article is the electronic one which can be found at:

https://doi.org/10.3762/bjnano.11.168 